\title{
Within-sample variability of $\delta^{13} \mathrm{C}$ and $\delta^{18} \mathrm{O}$ values of freshwater gastropod shells and the optimum number of shells to measure per sediment layer in the Paddenluch palaeolacustrine sequence, Germany
}

\author{
Karina Apolinarska • Mariusz Pełechaty • \\ Annette Kossler
}

Received: 27 February 2015/Accepted: 19 August 2015/Published online: 27 August 2015

(C) The Author(s) 2015. This article is published with open access at Springerlink.com

\begin{abstract}
This study aimed to: (1) investigate intrasample variability in the stable isotope composition $\left(\delta^{13} \mathrm{C}\right.$ and $\delta^{18} \mathrm{O}$ values) measured in several individual mollusc shells; and (2) determine the optimum number of individual mollusc shells required to obtain stable isotope values representative of the mean climate signal for a sediment sample. Seven hundred and six gastropod shells were analysed, representing eight species. These eight species were most abundant and consistently present in the sediment sequence of the Paddenluch outcrop, Brandenburg, northeast
\end{abstract}

Electronic supplementary material The online version of this article (doi:10.1007/s10933-015-9854-2) contains supplementary material, which is available to authorized users.

K. Apolinarska $(\bowtie)$

Institute of Geology, Faculty of Geographical and Geological Studies, Adam Mickiewicz University, Maków Polnych 16, 61-606 Poznan, Poland

e-mail: karinaap@amu.edu.pl

\section{Pełechaty}

Department of Hydrobiology, Faculty of Biology, Adam Mickiewicz University, Umultowska 89, 61-614 Poznan, Poland

e-mail: marpelhydro@poczta.onet.pl

\section{A. Kossler}

Institute of Geological Sciences, Branch Palaeontology,

Freie Universität Berlin, Malteserstr. 74-100,

12249 Berlin, Germany

e-mail: kossler@zedat.fu-berlin.de
Germany. Significant differences between minimum and maximum $\delta^{13} \mathrm{C}$ and $\delta^{18} \mathrm{O}$ values of the shells were recorded within all sediment samples and for all analysed species. Within the sediment samples, the greatest mean variability in both $\delta^{13} \mathrm{C}$ and $\delta^{18} \mathrm{O}$ values was found for Hippeutis complanatus, 5.84 and $5.23 \%$, respectively. The greatest intra-specific variability in $\mathrm{C}$ and $\mathrm{O}$ isotope values within individual sediment samples, however, was 10.2 and $6.8 \%$, respectively. Significant differences between minimum and maximum $\delta^{13} \mathrm{C}$ and $\delta^{18} \mathrm{O}$ values of individual mollusc shells within the same sediment sample are probably the result of population isotope variability, variations in species life span, thickness of the sediment sample, sediment accumulation rate, and environmental fluctuations during the time span when the sediment was deposited. Shells were randomly selected to determine the optimum number of shells necessary to obtain stable isotope values that are representative of the mean climate signal, from a $1-\mathrm{cm}$ sample of sediment. For each layer of the Paddenluch sediment sequence, 15 or more shells $(\mathrm{N} \geq 15)$ was the required sample size to provide representative isotope values and yield a reliable mean isotope value. Sample sizes with fewer shells displayed more variable mean $\delta^{13} \mathrm{C}$ and $\delta^{18} \mathrm{O}$ values. Stable isotope composition of the analyzed molluscs was speciesspecific, with differences in mean $\delta^{13} \mathrm{C}$ and $\delta^{18} \mathrm{O}$ values of 2.5 and $3 \%$, respectively. This illustrates the need to use mono-specific samples throughout a sediment sequence to generate reliable data. 
Keywords C and O isotope variability - Freshwater gastropod shells $\cdot$ Sediment sample .

Palaeolimnology · Quaternary

\section{Introduction}

Carbon and oxygen stable isotope composition $\left(\delta^{13} \mathrm{C}\right.$ and $\delta^{18} \mathrm{O}$ ) of mollusc shells is used widely in palaeolimnological studies to reconstruct past environments. The stable isotope composition of shells generally follows the carbon and oxygen isotope values of bulk carbonates in sediments and records palaeoclimate changes (Curtis et al. 1998; Yu 2000; Hailemichael et al. 2002). Nevertheless, vital effects, including species-specific food or habitat preferences can influence shell $\delta^{13} \mathrm{C}$ or $\delta^{18} \mathrm{O}$ values and must be considered (Shanahan et al. 2005; McConnaughey and Gillikin 2008). In most species, offsets from equilibrium values are species-specific, hence relative changes in $\mathrm{C}$ and $\mathrm{O}$ isotope values of shells recorded in sediment sequences reflect changes in the lake. In some gastropod species, however, food or habitat preferences change during the animal's life span and shell isotope values are not representative of the lake environment (Leng and Marshall 2004; Shanahan et al. 2005).

Precision of palaeoclimate reconstructions based on the $\delta^{13} \mathrm{C}$ and $\delta^{18} \mathrm{O}$ values of mollusc shells is dependent upon the method applied. One approach is to measure the stable isotope composition of individual mollusc shells (Jones et al. 2002; Escobar et al. 2010). This approach allows researchers to determine changes in isotope composition throughout the full length of the sediment sequence and assess variability of shell $\delta^{13} \mathrm{C}$ and $\delta^{18} \mathrm{O}$ values within sediment samples. Thus, it provides information on both longterm climate changes and short-term climate variability. The limiting factor for this approach is expense, because the cost for analysis of each sediment sample must be multiplied by the number of individual shells analysed. A common alternate approach involves use of homogenized shells from multiple freshwater molluscs, mostly gastropods, to average short-term (usually yearly, because most of the freshwater gastropods inhabiting temperate climate have a one to two-year life span, Frömming 1956; Taft et al. 2012) changes in lake conditions during accumulation of the sediment layer (Curtis et al. 1998; Hammarlund et al. 1999, 2002; Zanchetta et al. 1999; Anadón et al. 2002, 2006, 2008; Hodell et al. 2005; Apolinarska and Hammarlund 2009; DeFrancesco and Hassan 2013). In both approaches, the number of mollusc shells or opercula (calcitic opercula of the gastropod Bithynia tentaculata are frequently used because of their good preservation and abundance in lacustrine sediments) analysed per sediment sample typically range between one and 25. The number of shells analysed per sediment sample often differs among studies and is sometimes inconsistent within a study, because of changes in mollusc abundance over the length of the sediment sequence. Regardless of which approach is used, it is imperative to know how many shells should be analysed, either individually or in homogenized multi-shell samples, to obtain stable isotope values that are representative of the mean climate signal.

The freshwater molluscs that occur within a single sediment sample represent individuals from several generations, which precipitated their shells during different years. The number of generations within a sample is determined by the thickness of the sediment unit, the sediment accumulation rate and the lifespan of the gastropods. Theoretically, the thicker the sediment layer and/or the lower the sediment accumulation rate, the greater the number of shells that must be analysed. Two previous studies used individual gastropod shells to test the number of shells required to generate reliable (Jones et al. 2002) and high-frequency (Escobar et al. 2010) climate reconstructions.

Jones et al. (2002) tested how the range of isotope values from shells of Gyraulus piscinarium and Valvata cristata changed as the number of individual shells analysed increased. The authors sought to determine the required minimum number of shells from a 1-cm-thick sediment sample to represent the full range of isotope values. It was shown that six shells are sufficient for reliable interpretations of palaeoenvironmental change.

Escobar et al. (2010) used a more sophisticated statistical approach. They calculated the optimum number of shells of the gastropod, Pyrgophorus coronatus, and valves of the ostracod, Cytheridella ilosvayi, from lakes on the Yucatan Peninsula, that must be analysed for $\delta^{13} \mathrm{C}$ and $\delta^{18} \mathrm{O}$ to obtain a highfrequency climate reconstruction. The requisite number of gastropod shells differed among samples, from 
one to 43 per 1-cm-thick sediment layer. The range for ostracods was even larger, between two and 138. The approach applied by Escobar et al. (2010) is used more often in studies employing ostracods (Xia et al. 1997; Curtis et al. 1996, 1998; Hodell et al. 1995, 2005).

Regardless of the study approach used, the question is "What sample size is required for palaeoenvironmental reconstructions?" In the present study we aimed to: (i) investigate intra-sample variability of the stable isotope composition ( $\delta^{13} \mathrm{C}$ and $\delta^{18} \mathrm{O}$ values) of several individual mollusc shells; (ii) determine the optimum number of individual mollusc shells that must be analysed to obtain a stable isotope value that is representative of the mean climate signal for a sediment sample; and (iii) test the reliability of the two approaches mentioned above. Analyses for this study were performed on material from the Paddenluch sediment sequence, an easily accessible outcrop located in northeast Germany. The Paddenluch sediment sequence is already the subject of detailed palaeoenvironmental studies, including malacological investigations (Kossler 2010). Because the distribution of molluscs within the sediment sequence was well known, optimum sediment strata for sampling were easily identified for the present study.

\section{Geological setting}

The study site is located on the southern margin of the Barnim Plateau (east of Berlin, Brandenburg, northeastern Germany), about $2.3 \mathrm{~km}$ north of Rüdersdorf (Fig. 1). This slightly elevated moraine plateau was shaped by the Weichselian glaciation, and is therefore characterized by several glacial landforms. A specific glacial feature is the NE/SW-striking drainage system of the Barnim Plateau (Fig. 1), which can be traced back to subglacial meltwater channels of the Weichselian inland glaciers (Cepek in Jubitz 1993; Strahl 2005), within which meltwater drained to the Warszawa-Berlin ice margin valley ('Urstromtal'). Today, some large former channels are still filled with water, forming elongated lakes like Stienitz See, Kalksee, and Flakensee. The smaller channels filled in with sediments and were overgrown through the course of time. The Paddenluch is just such a former small channel, marked on older topographic maps as an elongated boggy depression (e.g. topographic map of the Kartographische Abtheilung der Königlich Preussischen Landesaufnahme 1877).
Another noteworthy geologic feature in the area is the salt structure of Rüdersdorf, which caused the uplift of the Triassic limestone (Hucke 1922; Jubitz 1993; Ahrens et al. 1995). For this reason, the Triassic limestone can be excavated by open-cast pit mining, today operated by Cemex OstZement GmbH. Reconstruction of the E/W-striking terminal slope of the Rüdersdorf pit, which was carried out in 2001, led to the cutting of the Paddenluch. By virtue of this fortunate circumstance, the sediment sequence of the Paddenluch was easily accessible and could be studied in detail (Strahl 2005; Kossler 2010). The previous studies showed that the sedimentary succession of the Paddenluch ranges from the Weichselian Pleniglacial (ca. 16,000 years BP), up into the Holocene. In contrast to other contemporaneous localities in Brandenburg (Strahl 2005), the Weichselian late glacial, with its interstadials (Meiendorf, Bølling, Allerød) and stadials (Oldest Dryas, Older Dryas, Younger Dryas), is completely preserved here. The sediments are mainly characterized by limnic, greyish, calcareous gyttjas, deposited under shallow-water conditions. Changes in the water table led to the accumulation of peaty deposits during the Allerød Interstadial and the Holocene (Strahl 2005; Kossler 2010). A further notable feature is the stratigraphic marker horizon of the Laacher See Tephra (12,880 varve years BP, Brauer et al. 1999) within the peaty deposits of the Allerød. In general, the sediments of the Paddenluch are extremely rich in fossils (e.g. gastropod shells, ostracod valves, plant macro-remains), which allow for detailed palaeoenvironmental and palaeoclimatic studies.

\section{Materials and methods}

Fieldwork

The easily accessible outcrop of the Paddenluch $\left(52^{\circ} 29^{\prime} 04^{\prime \prime} \mathrm{N}, 13^{\circ} 48^{\prime} 21^{\prime \prime} \mathrm{E}\right)$ enabled us to cut a block from the sedimentary succession (Fig. 2). A section of calcareous gyttja was chosen, which possessed numerous shells within the sediment. The exact stratigraphic position of the sediment block that was sampled, was based on the earlier, complex palaeoenvironmental studies of Paddenluch by Kossler (2010). The removed block was $33 \mathrm{~cm}$ high, $25 \mathrm{~cm}$ wide, and $15 \mathrm{~cm}$ deep; it was wrapped in plastic foil, packed in a 
Fig. 1 Location of the study site in Brandenburg, Germany. The red star indicates the position of the Paddenluch outcrop at the northern terminal slope of the open pit Rüdersdorf, east of Berlin. (Color figure online)

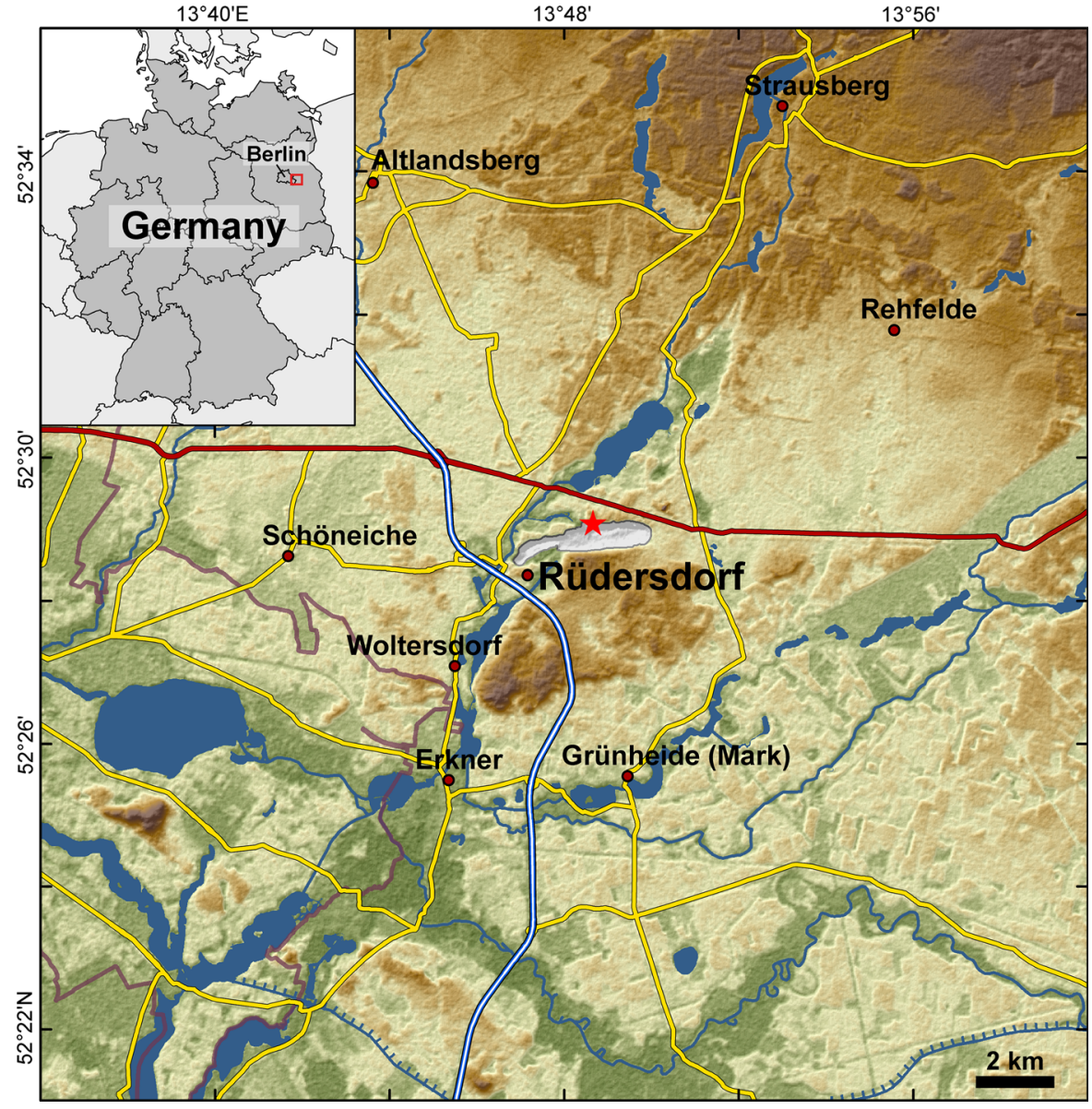

plastic box and transported to the Institute of Geology, Poznań, Poland.

\section{Laboratory study}

In the laboratory, the sediment block of calcareous gyttja was cut horizontally into 33 stratigraphic layers (samples), each 1-cm thick. The uppermost, youngest layer corresponds to sample No. 1, and the deepest, oldest layer corresponds to sample No. 33. Cutting the block into $1-\mathrm{cm}$-thick sections was facilitated by the presence of natural sediment layers that were clearly visible in the sequence. From all samples, each about $600 \mathrm{~cm}^{3}$ in volume, approximately one $\mathrm{cm}^{3}$ of sediment was taken for $\delta^{13} \mathrm{C}$ and $\delta^{18} \mathrm{O}$ isotope analyses of bulk carbonates. The rest of the samples were soaked in water to disaggregate the sediments and then passed through a sieve with a mesh of $0.5 \mathrm{~mm}$. After drying the residue, shells of molluscs were hand-picked, sorted, and counted under a low-power binocular microscope (Zeiss Stemi 2000-C).

Isotope analyses

On the basis of species diversity, shell abundance and shell preservation over the full length of the selected sediment block, shells of eight gastropod species from six sediment layers were chosen for $\delta^{13} \mathrm{C}$ and $\delta^{18} \mathrm{O}$ analyses (Table 1). Adult shells of equal size, from each gastropod species, were targeted for stable isotope analyses. This was done to minimize possible differences in $\delta^{13} \mathrm{C}$ and $\delta^{18} \mathrm{O}$ values of shells caused by the ontogenic stage of the gastropods. Adult shells were collected for all species except Lymnaea sp. Adult shells of Lymnaea sp. are usually relatively large, but thin-walled compared to adult shells of other species. Consequently, such shells are easily damaged and thus are rarely preserved in sediments. Also, sizes 


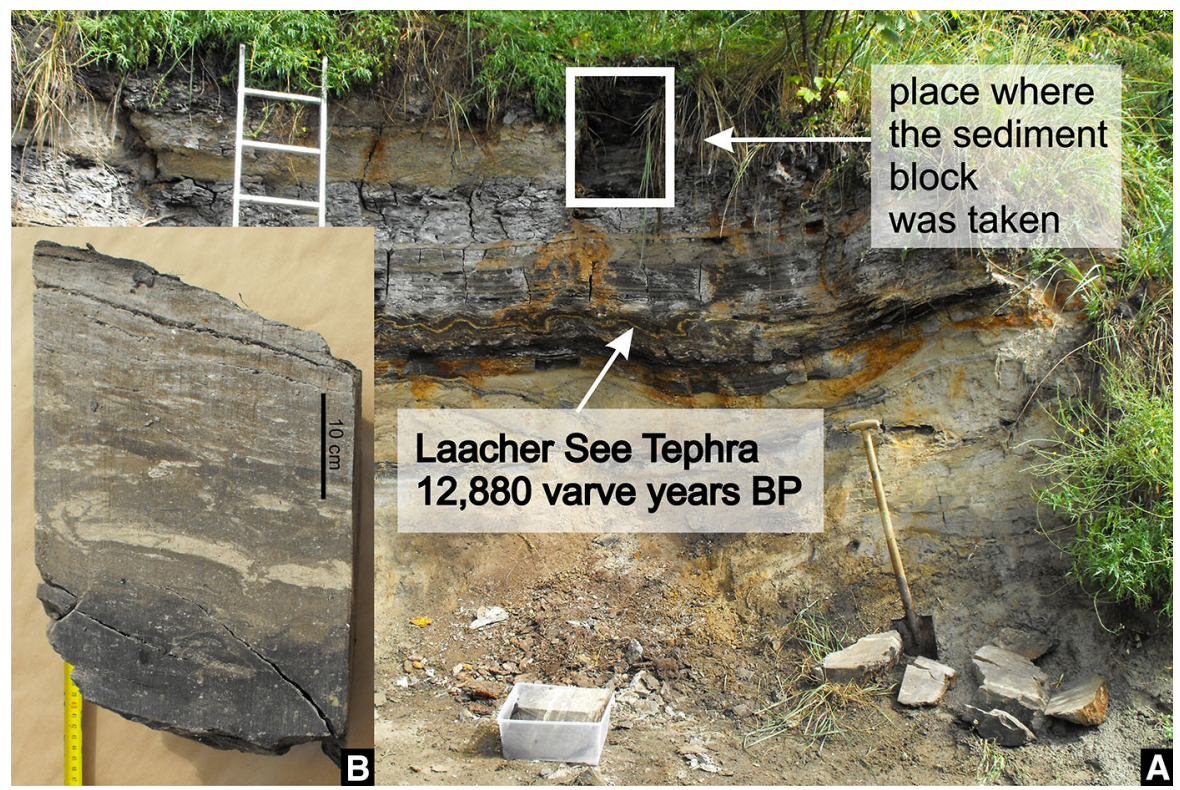

Fig. 2 Removal of the sediment block from the Paddenluch sequence. a Place where the sediment block was taken from the outcrop. b The isolated sediment block, which in the laboratory was cut into 331 -cm-thick sediment layers (=samples)

of adult shells within each gastropod species are not uniform, e.g. adult shells of Valvata piscinalis are between 5 and $7 \mathrm{~mm}$ high and 4.8 and $7 \mathrm{~mm}$ wide (Piechocki 1979). Thus, each shell was weighed using a RADWAG WAA $62 / \mathrm{X} / 1$ precision balance with a resolution of $0.00001 \mathrm{~g}$, to check for a possible correlation between stable isotope values and shell weight. Each isotope analysis was performed on an individual mollusc shell. Specifically, 20 shells of the eight gastropod species from the selected six sediment horizons were analysed (Table 1). Twenty shells were chosen based on the fact that rarely are more than 20 mono-specific shells present in samples from drill cores. The extracted shells were cleaned in $10 \% \mathrm{H}_{2} \mathrm{O}_{2}$ to remove adhering organic matter or sediment particles, and were subsequently air-dried. After weighing, the shells were ground to a fine powder using a mortar and pestle. The carbonate powder was placed in Eppendorf vials. The stable isotope composition of the gastropod shells was analysed at the Isotope Dating and Environment Research Laboratory in Warsaw, Poland. Carbonates were dissolved using $100 \%$ phosphoric acid (density 1.9 ) at $75{ }^{\circ} \mathrm{C}$ using a Kiel IV online carbonate preparation line connected to a ThermoFinnigan Delta + mass spectrometer. All values are reported as $\delta$ values, where $\delta=\left(\mathrm{R}_{\text {sample }} /\right.$ $\left.\mathrm{R}_{\text {standard }}-1\right) \times 1000$, in per mil relative to $\mathrm{V}-\mathrm{PDB}$, by assigning a $\delta^{13} \mathrm{C}$ value of $1.95 \%$ and a $\delta^{18} \mathrm{O}$ value of $-2.20 \%$ to NBS19. Reproducibility was checked on the basis of the long-term repeatability of NBS19 analysis and was better than \pm 0.07 and $0.12 \%$, for $\delta^{13} \mathrm{C}$ and $\delta^{18} \mathrm{O}$, respectively.

The 33 bulk sediment samples of the calcareous gyttja, which were also analysed isotopically as background data for the study objectives, were also dried, ground to a fine powder, and placed in Eppendorf vials. The $\delta^{13} \mathrm{C}$ and $\delta^{18} \mathrm{O}$ values of the calcareous sediment samples were measured using a Gas Bench II connected to a Finnigan MAT 253 gas source mass spectrometer (both Thermo Fisher) in the Institute of Geoscience at J.W. Goethe University in Frankfurt am Main, Germany. Analytical details are given in Spötl and Vennemann (2003). For a single analysis, 50-120 $\mu \mathrm{g}$ of the calcareous sediment were loaded into Labco exetainer vials. Carrara marble was analysed with the samples, and its isotopic composition was calibrated against NBS 19 (Fiebig et al. 2005). Results are expressed as per mil (\%) deviations from the PDB carbonate standard and have an analytical precision of $\pm 0.06 \%$ for carbon and $\pm 0.08 \%$ for oxygen. 
Table 1 Carbon and oxygen stable isotope composition of bulk carbonates and gastropod shells

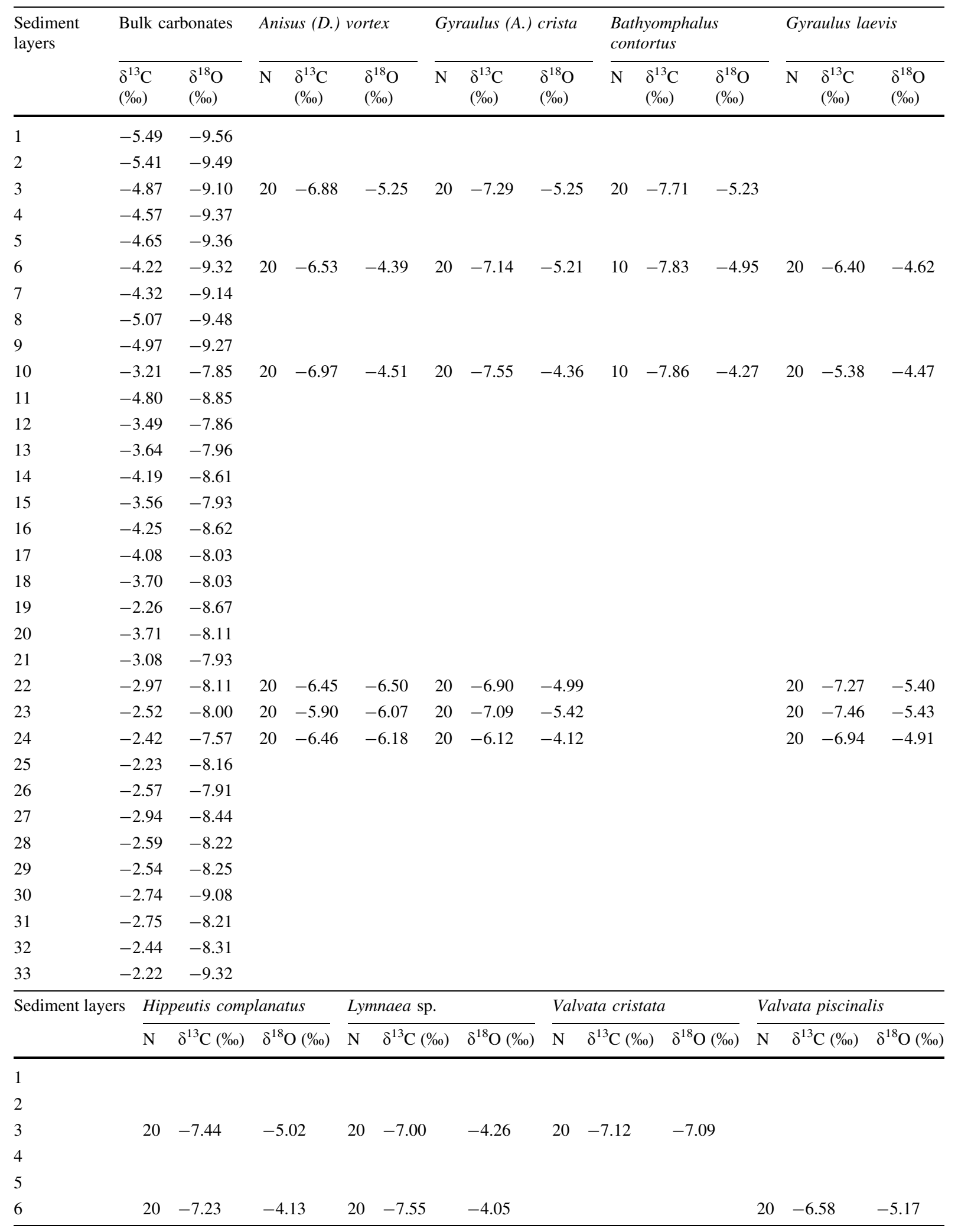


Table 1 continued

\begin{tabular}{|c|c|c|c|c|c|c|c|c|c|c|c|c|}
\hline \multirow[t]{2}{*}{ Sediment layers } & \multicolumn{3}{|c|}{ Hippeutis complanatus } & \multicolumn{3}{|c|}{ Lymnaea sp. } & \multicolumn{3}{|c|}{ Valvata cristata } & \multicolumn{3}{|c|}{ Valvata piscinalis } \\
\hline & $\mathrm{N}$ & $\delta^{13} \mathrm{C}(\%)$ & $\delta^{18} \mathrm{O}(\%)$ & $\mathrm{N}$ & $\delta^{13} \mathrm{C}(\%)$ & $\delta^{18} \mathrm{O}(\%)$ & $\mathrm{N}$ & $\delta^{13} \mathrm{C}(\%)$ & $\delta^{18} \mathrm{O}(\%)$ & $\mathrm{N}$ & $\delta^{13} \mathrm{C}(\%)$ & $\delta^{18} \mathrm{O}(\%$ \\
\hline \multicolumn{13}{|c|}{7} \\
\hline \multicolumn{13}{|l|}{8} \\
\hline \multicolumn{13}{|l|}{9} \\
\hline 10 & 20 & -6.60 & -3.59 & & & & & & & 20 & -7.36 & -4.71 \\
\hline \multicolumn{13}{|l|}{11} \\
\hline \multicolumn{13}{|l|}{12} \\
\hline \multicolumn{13}{|l|}{13} \\
\hline \multicolumn{13}{|l|}{14} \\
\hline \multicolumn{13}{|l|}{15} \\
\hline \multicolumn{13}{|l|}{16} \\
\hline \multicolumn{13}{|l|}{17} \\
\hline \multicolumn{13}{|l|}{18} \\
\hline \multicolumn{13}{|l|}{19} \\
\hline \multicolumn{13}{|l|}{20} \\
\hline \multicolumn{13}{|l|}{21} \\
\hline 22 & 20 & -5.58 & -4.89 & 10 & -5.43 & -4.60 & 15 & -6.61 & -6.88 & 20 & -5.92 & -5.60 \\
\hline 23 & 20 & -5.96 & -4.73 & 10 & -6.17 & -5.01 & & & & 20 & -6.29 & -5.05 \\
\hline 24 & 20 & -5.85 & -3.56 & 10 & -6.02 & -4.92 & & & & 20 & -6.62 & -5.25 \\
\hline
\end{tabular}

$\delta^{13} \mathrm{C}$ and $\delta^{18} \mathrm{O}$ values of bulk carbonates were measured in $1-\mathrm{cm}$ thick sediment layers continuously over the full length of the sediment section. Stable isotope composition of mollusc shells is presented as mean arithmetic value (preferably $\mathrm{N}=20$ ). Mollusc species, which were most abundantly present within the sediments, were selected from six 1-cm-thick sediment layers. All the values are reported in \%o relative to V-PDB

\section{AMS radiocarbon dating}

Chronology of the selected sediment section was based on three AMS ${ }^{14} \mathrm{C}$ dates on terrestrial plant macro-remains (Populus bud scales), measured at the Poznań Radiocarbon Laboratory (Table 2). Conventional radiocarbon ages were calibrated using the OxCal v4.2.4 program (Bronk Ramsey and Lee 2013) with the atmospheric data from Reimer et al. (2013). All ages provided in the text are calibrated.

\section{Statistical analyses}

For all selected gastropod species, basic descriptive statistics were calculated using STATISTICA 10 software (StatSoft Inc., Tulsa, Oklahoma, USA). Species within an individual sediment sample were compared by means of diagrams that present mean $\delta^{13} \mathrm{C}$ and $\delta^{18} \mathrm{O}$ values and the range between their minimum and maximum values. Relationships between isotope values and the weight of shells were 
Table 2 AMS ${ }^{14} \mathrm{C}$ dates obtained from terrestrial macrofossils of the Paddenluch sediment sequence, measured at the Poznań Radiocarbon Laboratory

\begin{tabular}{llllllll}
\hline $\begin{array}{l}\text { No. of the } \\
\text { dated sediment } \\
\text { layer }\end{array}$ & $\begin{array}{l}\text { Dated } \\
\text { material }\end{array}$ & Lab. no. & $\begin{array}{l}\text { AMS }{ }^{14} \mathrm{C} \text { a } \\
\text { BP }\end{array}$ & $\begin{array}{l}\text { Cal. a BP } \\
(2 \sigma \text { range) }\end{array}$ & $\begin{array}{l}\text { Cal. a BP used } \\
\text { in age model }\end{array}$ & $\begin{array}{l}\text { Sediment } \\
\text { accumulation } \\
\text { rate (mm/year) }\end{array}$ & $\begin{array}{l}\text { Sediment } \\
\text { accumulation } \\
\text { rate (year/cm) }\end{array}$ \\
\hline 02 & $\begin{array}{l}\text { Populus bud scales } \\
16\end{array}$ & Poz-59379 & $9660 \pm 50$ & $11,208-10,786$ & 11,093 & 0.86 & 11.6 \\
25 & Populus bud scales & Poz-59381 & $9850 \pm 50$ & $11,351-11,199$ & 11,255 & \\
16
\end{tabular}

Conventional radiocarbon ages were calibrated using the OxCal v4.2.4 program (Bronk Ramsey and Lee 2013) with the atmospheric data from Reimer et al. (2013). Sediment accumulation rates were estimated based on the chronology

tested using Pearson's correlation, with $P<0.05$ accepted as statistically significant.

The number of individual shells required to obtain mean $\delta^{13} \mathrm{C}$ and $\delta^{18} \mathrm{O}$ values representative for the sediment layers was tested using a random sampling method. For two species, Anisus (Disculifer) vortex and Gyraulus (Armiger) crista, two, three, five, ten, and 15 shells were selected randomly from the generated data set, i.e. out of the 20 shells (Table 1). The mean, minimum, maximum and range of the isotope values, standard deviations and standard errors were calculated for each of the randomly selected samples. These statistics are presented graphically as box and whisker diagrams and histograms, to illustrate the relationships between the number of shells in a sample and the scatter of the isotope values. In addition, to provide insights into the scatter of mean values, which depend on the quantity of shells, a further random selection was performed to exemplify the successive mean values of two, three, four, ..., up to 20 shells. Results of these analyses are presented as scatter diagrams (Fig. 7). Shells were drawn from the individual samples using an on-line randomizing program (http://www.losowe.pl/liczba).

We calculated the optimum quantity of shells, sensu Escobar et al. (2010), which is the minimum number of individuals that achieves acceptable errors for each stratigraphic level. Similar to previous works, we assumed an acceptable error to be $10 \%$, following the formula given in the cited paper:

$n=(t \times s / E)^{2}$

where $t$ is the Student's $t$ value for a given level of significance, $s$ is the standard deviation, and $E$ is the acceptable error. The level of significance for all sediment horizons was set at $\alpha=0.01$.

Because the calculated quantity of shells using the formula mentioned above turned out to be unrealistic for standard palaeoecological studies, as discussed below, we performed our calculations for only one species, Anisus (D.) vortex, and for all samples in which this species occurred.

\section{Results}

\section{Chronology}

By the time we conducted fieldwork, the early Holocene age of the sediment block sampled from the Paddenluch had already been established by Strahl (2005), Kossler (2010). The Preboreal age of the sediment block was confirmed by dating three additional AMS radiocarbon samples, which provided a detailed chronology and allowed us to calculate the average sediment accumulation rate (Tables 2, 3). According to the determined chronology, the $1-\mathrm{cm}$ sampling interval corresponds to approximately 16 years for the older part (11,399-11,255 cal a BP) of the sequence and to 11.6 years for the younger part of the sedimentary succession $(11,255-11,093 \mathrm{cal} \mathrm{a}$ $\mathrm{BP})$.

Stable isotope composition of bulk carbonates

Carbon and oxygen stable isotope composition of the calcareous bulk sediment samples changed within the studied time frame, between -5.49 and $-2.22 \%$ and -9.56 and $-7.57 \%$, respectively (Fig. 3). The relation between $\delta^{13} \mathrm{C}$ and $\delta^{18} \mathrm{O}$ values varied over the length of the sedimentary succession. In its lower part, carbon and oxygen stable isotope composition revealed opposite trends, whereas values in the upper part showed a positive correlation and similar decreasing trends toward the top of the sequence. 


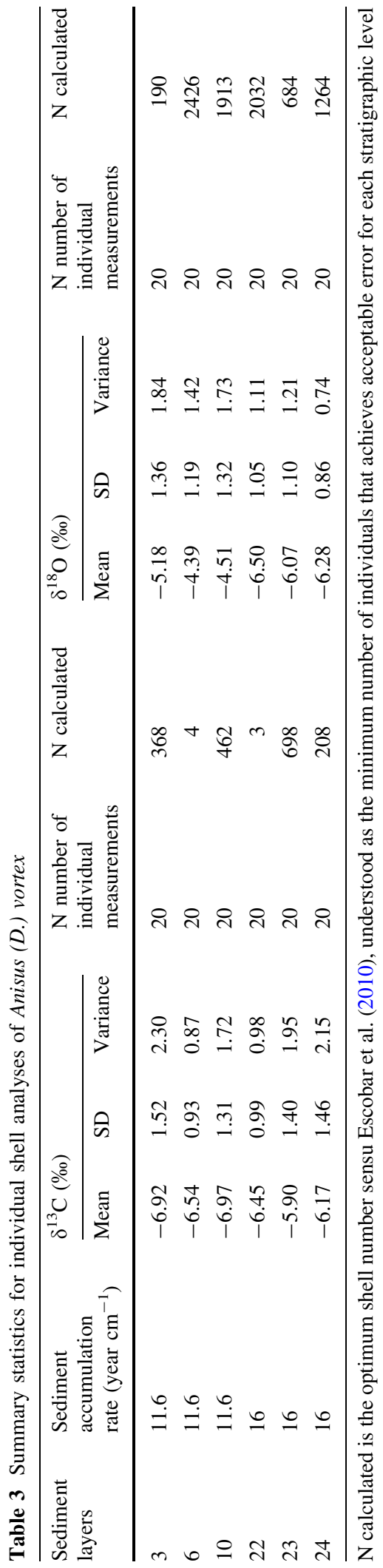

Stable isotope composition of mollusc shells

The 706 gastropod shells analysed in this study represent eight mollusc species that were most abundantly and continuously present within the sediments, i.e. Anisus (Disculifer) vortex (Linnaeus), Gyraulus (Armiger) crista (Linnaeus), Bathyomphalus contortus (Linnaeus), Gyraulus laevis (Alder), Hippeutis complanatus (Linnaeus), Lymnaea sp., Valvata cristata O.F. Müller and Valvata piscinalis (O.F. Müller) (Table 1).

Intra-sample variability in $\delta^{13} \mathrm{C}$ and $\delta^{18} \mathrm{O}$ values of mollusc shells

For all species, significant differences between minimum and maximum $\delta^{13} \mathrm{C}$ and $\delta^{18} \mathrm{O}$ values of the shells were recorded (Fig. 4). The lowest mean variability in both $\delta^{13} \mathrm{C}$ and $\delta^{18} \mathrm{O}$ values belonged to Valvata cristata, 3.36 and $2.75 \%$, respectively. However, this snail was also the least abundant in the assemblage (Table 1). The greatest mean variability in both $\delta^{13} \mathrm{C}$ and $\delta^{18} \mathrm{O}$ values was from Hippeutis complanatus, 5.84 and $5.23 \%$, respectively. The intra-specific variability in $\mathrm{C}$ and $\mathrm{O}$ isotope values within individual sediment samples was much greater compared to the above characterized mean variability in $\delta^{13} \mathrm{C}$ and $\delta^{18} \mathrm{O}$ values. Again, the greatest differences between the minimum and maximum isotope values reached $10.2 \%$ for $\delta^{13} \mathrm{C}$ and $6.8 \%$ for $\delta^{18} \mathrm{O}$, respectively, and were measured in the shells of $H$. complanatus (Fig. 4). Figure 4 illustrates not only the intra-specific variation of the isotope values and the differences between the gastropod species, it also shows a sorting of species, in each case ranging from the least to the most depleted in ${ }^{13} \mathrm{C}$ and ${ }^{18} \mathrm{O}$. It became obvious that for the different sediment layers there is no uniform order of species (Fig. 4).

Optimum number of mollusc shells per sediment sample for isotope analyses

The random method applied here to select gastropod shell samples to determine the optimum number of mollusc shells per sediment sample necessary for statistically significant isotope analyses yielded very similar observations across species. Thus, to simplify the discussion, two species, Anisus (D.) vortex and Gyraulus (A.) crista, both present in all sampled 
sediment layers, were chosen for detailed consideration. Mean, range, and standard deviation (SD) of the isotope values differed between the randomly selected shell samples ( $\mathrm{N}=2,3,5,10,15,20$; Fig. 5). Statistics calculated for all samples composed of 10 or less shells differed from values obtained from samples composed of 20 shells, i.e. the maximum number of analysed mono-specific shells from one sediment layer (Fig. 5). This showed that the range of the data is related to the number of selected shells (Fig. 6). In most random samples, mean isotope values stabilized when 15 or more shells were analysed. Similarly, the difference between the minimum and maximum isotope values in random samples composed of 15 shells is close to the maximum range measured on 20 shells (Fig. 5).

\section{Discussion}

Intra-sample variability in $\delta^{13} \mathrm{C}$ and $\delta^{18} \mathrm{O}$ values of mollusc shells

In the present study, significant intra-sample variability in $\delta^{13} \mathrm{C}$ and $\delta^{18} \mathrm{O}$ values of the gastropod shells was observed, with the maximum intra-specific differences between minimum and maximum $\delta^{13} \mathrm{C}$ and $\delta^{18} \mathrm{O}$ values of 10.2 and $6.8 \%$, respectively (Fig. 4). These differences are approximately three times greater than the changes in $\delta^{13} \mathrm{C}(\sim 3 \%)$ and $\delta^{18} \mathrm{O}(\sim 2 \%)$ values measured in the calcareous bulk sediment samples over the length of the sedimentary succession (Fig. 3). Thus, application of these $\delta^{13} \mathrm{C}$ and $\delta^{18} \mathrm{O}$ values of individual mollusc shells in reconstructions of the past environment or climate would result in erroneous conclusions.

The shell samples in each sediment layer represent the gastropods that inhabited the former lake bottom or macrophytes within an area of $0.0375 \mathrm{~m}^{2}$, based on the size of the sampled sediment block, $25 \times 15 \mathrm{~cm}$. The gastropod species chosen for this study represent a typical assemblage for a densely vegetated lake littoral zone. Gastropods live on the macrophytes, and only during the winter season are molluscs found on the lake bottom, usually within the detritus. It has been shown by different authors, including Lorrain et al. (2005), Geist et al. (2005), Apolinarska (2013), that variability in $\delta^{13} \mathrm{C}$ and $\delta^{18} \mathrm{O}$ values among bivalve mollusc shells within a subpopulation, i.e. the variability among individual molluscs taken from defined areas in a lake or a river, can be significant. The difference in isotope values among shells of living specimens of Dreissena polymorpha taken from different sites within the Lake Lednica littoral zone (Apolinarska 2013) ranged between 0.6 and $1.3 \%$ for $\delta^{13} \mathrm{C}$ and 0.4 and $2.8 \%$ for $\delta^{18} \mathrm{O}$ (the minimum and maximum range of values were measured in several subpopulations). The difference between the minimum and maximum isotope values of shells of living freshwater gastropods taken from the same lake varied within a species, between 0.15 and $3.92 \%$ for $\delta^{13} \mathrm{C}$ and 0.12 and $1.86 \%$ for $\delta^{18} \mathrm{O}$ (Apolinarska and Pełechaty, unpublished data). Shells of both $D$. polymorpha and gastropods were collected from macrophytes that covered defined zones of the lake bottom, i.e. each zone had an area of $0.0225 \mathrm{~m}^{2}$. A similar sampling method was used to minimize the environmental variability influencing shell isotope values, and to determine the range of isotope values in mono-specific mollusc shells within a microhabitat in a lake.

Depending on the energy of the sedimentation environment, bioturbation within the specific subaquatic environment, and possible reworking of empty shells from different microhabitats within the palaeolake, the thanatocoenosis can be composed of shells from different sub-habitats within a lake, which were probably influenced by different physical and chemical characteristics, including isotopes. It must be emphasized that the stable isotope variability within populations inhabiting Lake Lednica was greater than the variability measured between shells collected from macrophytes in restricted areas of the lake bottom. The population of Dreissena polymorpha in Lake Lednica was characterized by ranges of $3.64 \%$ for $\delta^{13} \mathrm{C}$ and $3.17 \%$ for $\delta^{18} \mathrm{O}$ (Apolinarska 2013). In populations of freshwater gastropods form Lake Lednica, the difference measured between the minimum and maximum isotope values for a given species within all sites was between 0.53 and $6.01 \%$ for $\delta^{13} \mathrm{C}$, with a mean value of $3.33 \%$, and between 0.12 and $2.94 \%$ for $\delta^{18} \mathrm{O}$, with a mean value $1.53 \%$ (Apolinarska and Pełechaty unpublished data).

A fraction of the $\mathrm{C}$ and $\mathrm{O}$ isotope variability among mono-specific mollusc shells within a sediment layer (Fig. 4) can be explained by intra-population or intrasubpopulation isotopic variability. The data clearly show that the carbon and oxygen isotope values of 
Fig. $3 \delta^{13} \mathrm{C}$ and $\delta^{18} \mathrm{O}$ values of bulk carbonate and mollusc shell samples from the 33 sediment layers of the sediment block from the Paddenluch sequence. $\delta^{13} \mathrm{C}$ and $\delta^{18} \mathrm{O}$ values of bulk carbonate were continuously measured for every 1 -cm-thick sediment layer. Stable isotope composition of mollusc shells is presented as the mean arithmetic value (preferably $\mathrm{N}=20$ ) for each species

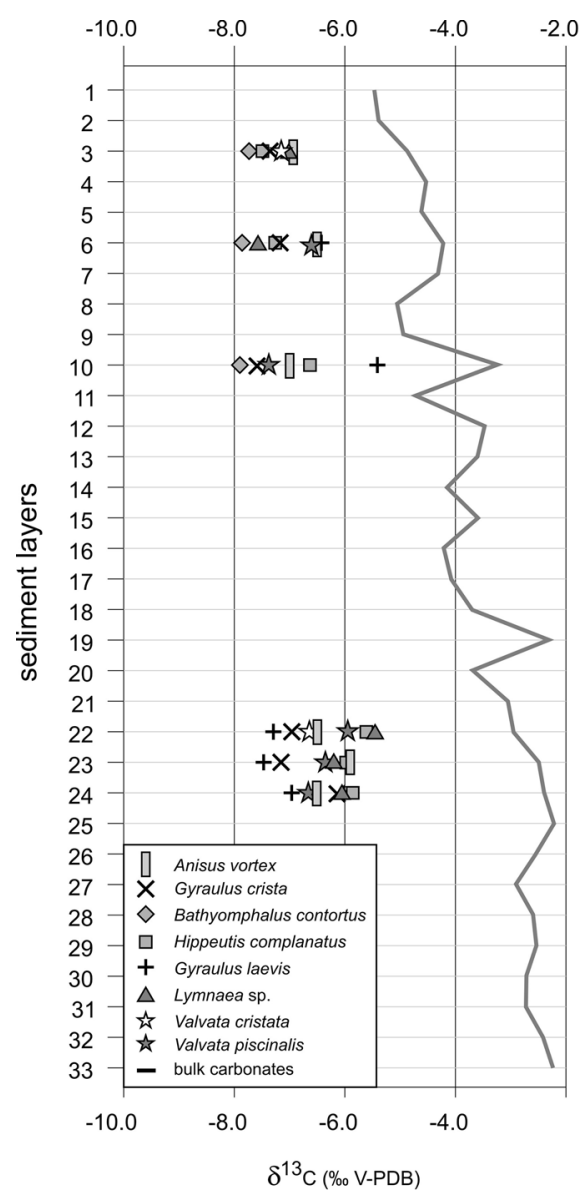

subfossil mollusc shells can be situated somewhere between the low and high end of the isotopic variability of the entire population; thus, the isotope values of an individual shell or few shells cannot be regarded as being representative of the whole population.

Another factor that can influence isotope values and their variation among mono-specific shells is the ontogenic stage of individual molluscs. Most freshwater gastropods have a one- to two-year life span (Frömming 1956; Taft et al. 2012), but only some grow to their full size. Consequently, shells of different size and different ontogenic stages are found in the sediments. Such shells have different isotope signatures because of variations in the $\delta^{13} \mathrm{C}$ of DIC and $\delta^{18} \mathrm{O}$ of water, and water temperature, during the year (Taft et al. 2012, 2013). Although all the shells selected for isotope analyses, except Lymnaea sp., belonged to adult individuals of equal size for each species, each shell was weighed and the weight was related to the isotope values (Electronic Supplementary Material [ESM] Table 1). Neither $\delta^{13} \mathrm{C}$ nor $\delta^{18} \mathrm{O}$ values of the shells revealed a statistically significant correlation with shell weight. Therefore, even though we cannot rule out the possibility that slight differences in shell size influence the isotopic composition of the shell, we suspect this influence is negligible.

Assemblages of molluscs that occur within a sediment layer comprise several generations that precipitated their shells during different years and therefore were probably exposed to different environmental conditions that influence shell $\delta^{13} \mathrm{C}$ and $\delta^{18} \mathrm{O}$ values. Again, the number of generations is roughly correlated with the thickness of the sediment layer, the sediment accumulation rate, and the potential lifespan of the molluscs. Because most freshwater gastropod species have a 1- to 2-year life span (Frömming 1956), it is assumed that every sediment layer contains 

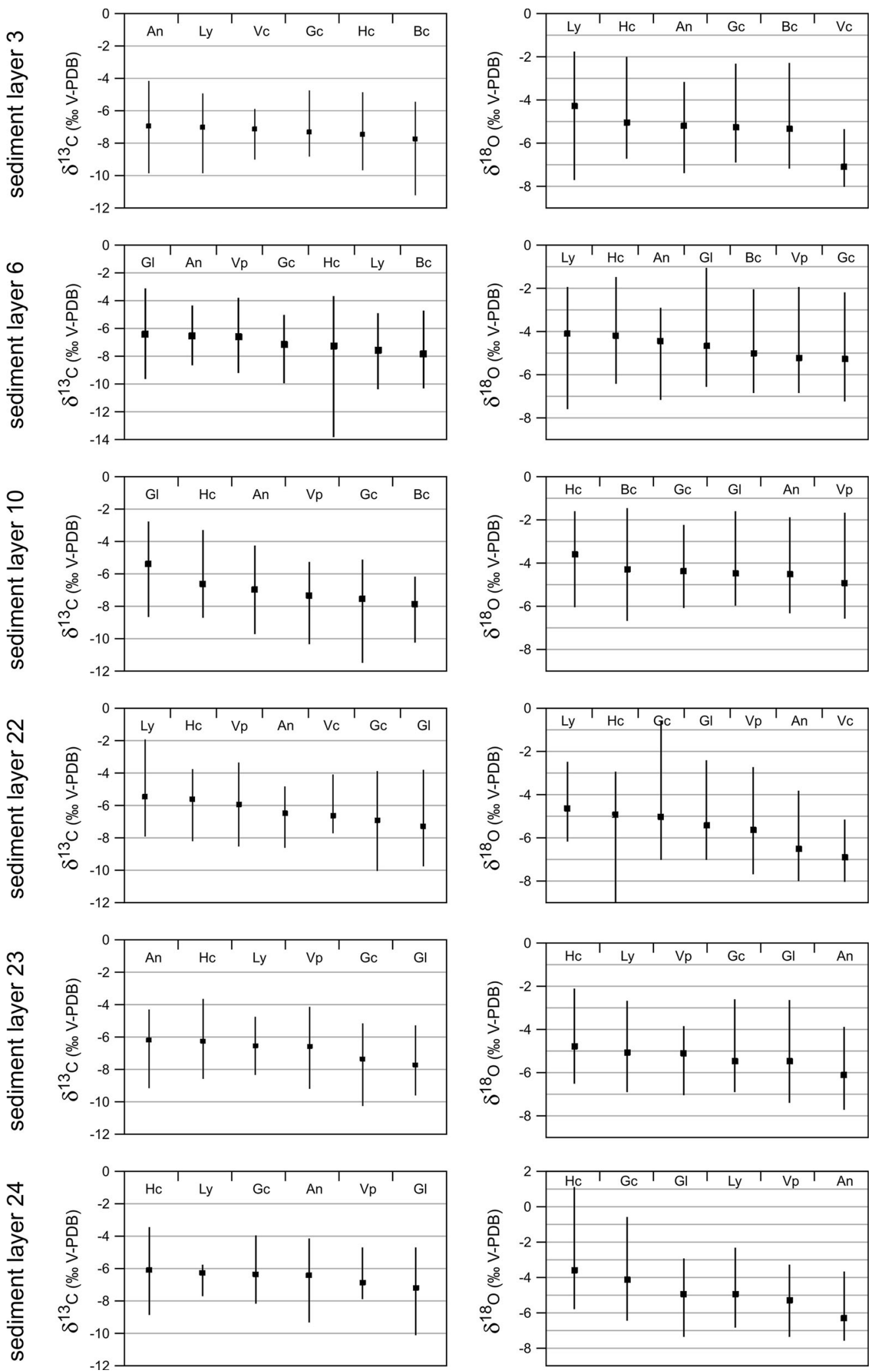
4Fig. 4 Mean arithmetic values and the differences between the minimum and maximum $\delta^{13} \mathrm{C}$ and $\delta^{18} \mathrm{O}$ values measured in the gastropod shells of six selected sediment layers (values are presented separately for each of the layers). In each image, species are arranged according to their mean isotope values, from the least to the most depleted in ${ }^{13} \mathrm{C}$ and ${ }^{18} \mathrm{O}$, respectively. Abbreviations used for gastropod species: An-Anisus (D.) vortex, $\mathrm{Gc}-$ Gyraulus (A.) crista, $\mathrm{Bc}-$ Bathyomphalus contortus, Gl-Gyraulus laevis, Hc-Hippeutis complanatus, LyLymnaea sp., Vc_Valvata cristata, Vp_Valvata piscinalis

several generations of gastropods, which were precipitated during different years. In the present study, each 1-cm-thick sediment layer represents 11.6-16 years of sediment accumulation (Table 2). Theoretically, increased resolution of sediment samples will improve the precision of palaeoclimate reconstructions, because differences between the minimum and maximum carbon and oxygen stable isotope values measured in mollusc shells from high-resolution sediment samples (i.e. short time spans) should decrease. This is only true, however, if environmental variability during accumulation of each sediment layer remains relatively constant, i.e. the maximum range of isotope values in each sediment layer is constant, which is rarely the case in lacustrine sediments. Changes in the range of $\delta^{13} \mathrm{C}$ and $\delta^{18} \mathrm{O}$ values in shells from different sediment layers can be used as an indicator of environmental variability. Escobar et al. (2010) showed that the $\delta^{13} \mathrm{C}$ and $\delta^{18} \mathrm{O}$ variability among individual gastropod shells and ostracod carapaces from sediment layers may provide information on climate variability during the time period of sediment deposition. The authors distinguished between dry and humid climate on the Yucatan Peninsula during the Terminal Classic Maya Period using the $\delta^{18} \mathrm{O}$ variability among individual gastropod shells and ostracod carapaces from different stratigraphic levels. Relatively dry periods were shown to be persistently dry based on low $\delta^{18} \mathrm{O}$ variability. In contrast, relatively wet periods were characterized by alternating wet and dry phases, indicated by larger differences between the minimum and maximum isotope values.

The present study shows that the mean sediment accumulation rate of the studied section of the Paddenluch outcrop increased in the upper part of the sequence (Table 2). We hypothesized that the higher sedimentation rate would lead to less condensed sediment layers and, consequently, to the recording of fewer gastropod generations and possibly decreased differences between the minimum and maximum isotope values, as measured in individual gastropod shells from a single sediment layer. Our data, however, failed to support this notion. The increase in the sediment accumulation rate from $0.63 \mathrm{~mm} \mathrm{a}^{-1} \quad\left(16\right.$ year $\left.\mathrm{cm}^{-1}\right)$ to $0.86 \mathrm{~mm} \mathrm{a}^{-1}$ $\left(11.6 \mathrm{a} \mathrm{cm}^{-1}\right)$ was not associated with a decrease in the difference between the minimum and maximum isotope values of individual shells (Fig. 4). Rather, greater differences were observed. It is possible that the upper part of the sequence was affected by multiple environmental conditions that influenced the shell isotope values. It is likely that the large variation can be related to shallower water levels in the lake at that time. A decline in lake level during the Preboreal is also supported by sedimentological and palaeontological data (Kossler 2010). In general, shallow lakes are characterized by more variable environmental conditions than deep, stratified lakes. This environmental variability in shallow lakes is a consequence of, among others factors, higher susceptibility to changing climate conditions, a greater influence on biotic life from more erratic water temperatures, and less stable or absent vertical thermal stratification.

Optimum number of mollusc shells per sediment layer for representative mean isotope values

Considering the large variability in isotope values of gastropod shells in the sediment layers, the question is, "how many individual shells should be analysed to obtain representative mean isotope values for a sediment layer?" Here, the method of random shell sampling was applied to test the mean isotope values, the range of the isotope values and the standard deviation in samples composed of two, three, five, ten, and 15 shells from the data set, i.e. out of 20 shells (Fig. 5). This maximum number of 20 mono-specific shells per 1-cm-thick sediment layer was used because in most palaelimnological studies using sediment cores, the number of mono-specific shells from a sediment layer rarely exceeds 20 .

From the mean ranges in $\delta^{13} \mathrm{C}$ and $\delta^{18} \mathrm{O}$ values (Fig. 6), we suggest that the differences between the minimum and maximum isotope values measured in 20 mono-specific shells per $1-\mathrm{cm}$ sediment layer probably represent the full range of isotopic values, 
Anisus (D.) vortex
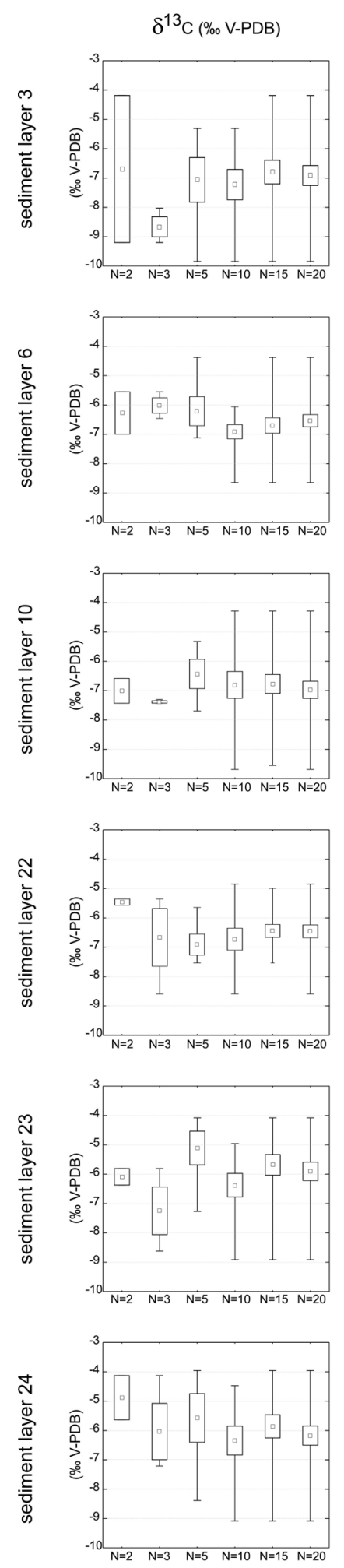
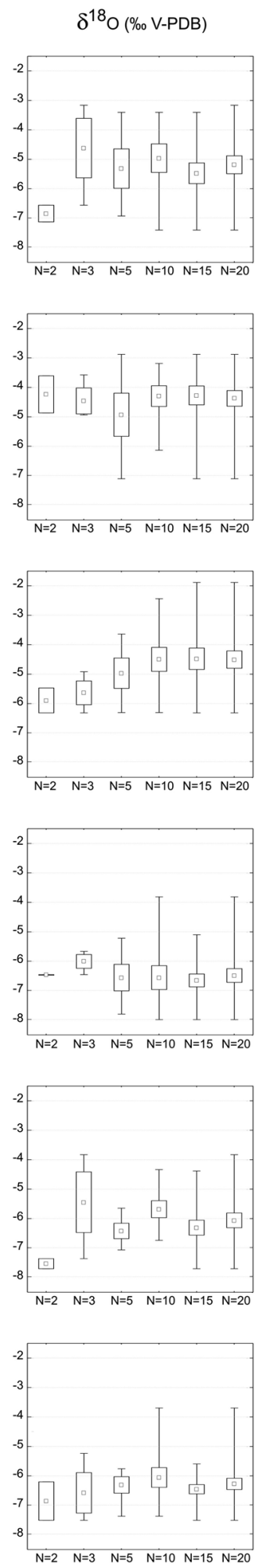

Gyraulus (A.) crista
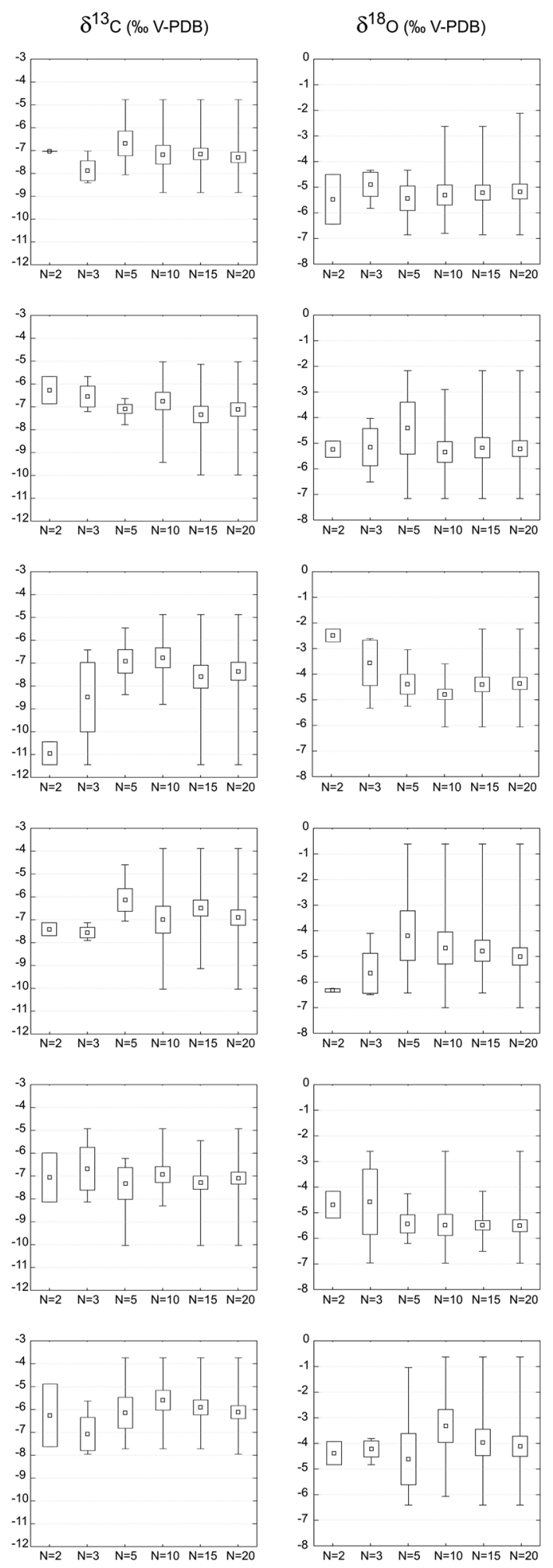
४Fig. 5 Mean isotope values, standard deviation (SD) and ranges of $\delta^{13} \mathrm{C}$ and $\delta^{18} \mathrm{O}$ values calculated for Anisus (D.) vortex and Gyraulus (A.) crista in the selected six layers on the basis of 2, 3, 5, 10 and 15 randomly selected shells from samples, which consisted of at least 20 shells

because the differences in range values between $\mathrm{N}=15$ and $\mathrm{N}=20$ shells are minor compared to the range in smaller sample sizes (Figs. 5, 6). Nevertheless, a wider range of values might be expected, according to the calculation of Escobar et al. (2010), who pointed out that even larger sample sizes should be considered in such studies. In the present study, however, the maximum number of shells $(\mathrm{N}=20)$ seems to cover the spectrum of possible values (Figs. 5, 6) and the data indicate the maximum range was probably approached.

Our results differ significantly from the results of a study by Jones et al. (2002), in which the variability in $\delta^{13} \mathrm{C}$ and $\delta^{18} \mathrm{O}$ values was measured in two freshwater gastropod species, Gyraulus piscinarium and Valvata cristata, from Lake Gölhisar, Turkey. Based on the stable isotope composition of randomly selected shells from eight 1-cm-thick sediment layers, Jones et al. (2002) concluded that only five or six shells of Gyraulus piscinarium or Valvata cristata need be analysed isotopically to reveal the maximum range of $\delta^{18} \mathrm{O}$ values. In our study, the mean isotope values, the range of the isotope values, and the standard deviation (SD) differ significantly in most samples with 5 randomly selected shells, compared to samples composed of 20 shells (Figs. 5, 6). Moreover, the mean values, the range of values and the SD values were highly dependent on the stable isotope composition of the randomly selected shells. In samples composed of only five shells, the listed measures differed between successive random selections of shells. The variance in the sediment accumulation rate between the Paddenluch sediment sequence and Lake Gölhisar, $0.63-0.86 \mathrm{~mm} \mathrm{a}^{-1}$, and $0.3-1.5 \mathrm{~mm} \mathrm{a}^{-1}$, respectively, could explain the differences in the range of the isotope values between the two studies, and thus influence the number of shells required to obtain the maximum range of isotope values. However, results of Jones et al. (2002) indicate there was no relation between the sediment accumulation rate and the variability in the measured $\delta^{18} \mathrm{O}$ values, i.e. increased sedimentation rate did not result in decreased isotope variability. Also, the range in $\delta^{18} \mathrm{O}$ values in shells of $G$. piscinarium and V. cristata was comparable to our data, i.e. in samples with 10 analysed shells, the range varied between 2.8 and $5.79 \%$. Because Jones et al.
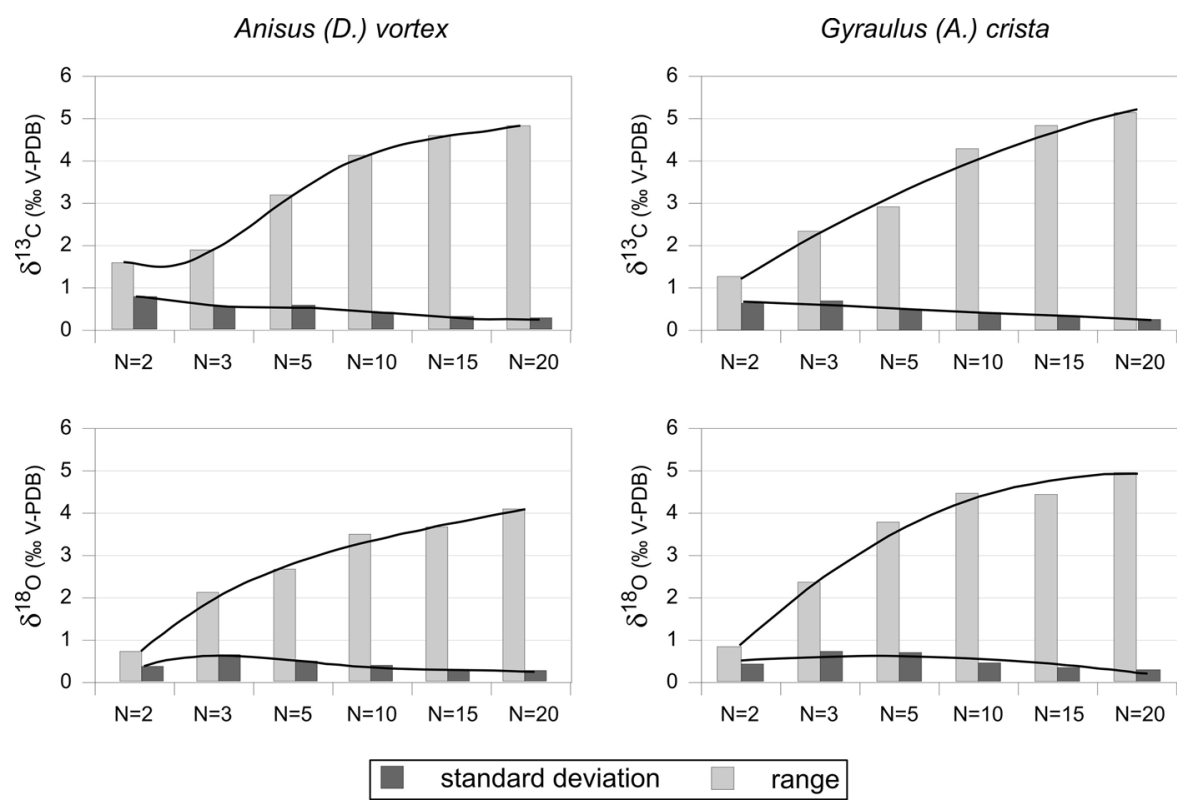

Fig. 6 Changes in the mean isotope range and the standard deviation (SD) of the randomly selected shells of Anisus (D.) vortex and Gyraulus (A.) crista. The presented isotope values are the mean values for the six selected sediment layers 
Anisus (D.) vortex
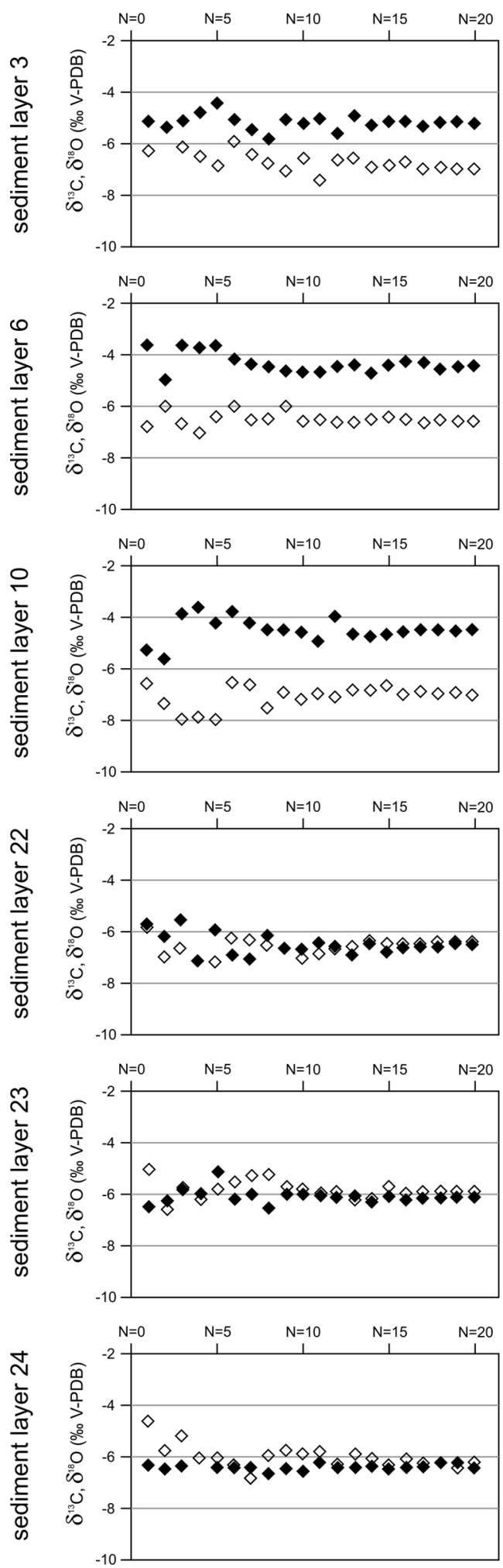

Gyraulus (A.) crista
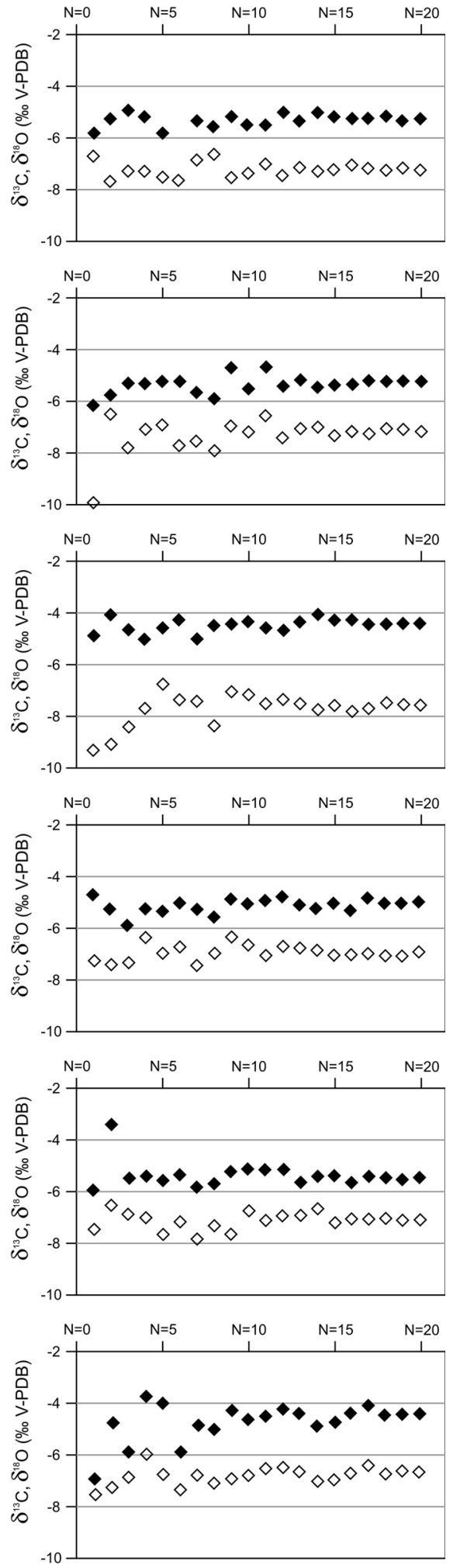
4Fig. 7 Mean $\delta^{13} \mathrm{C}$ and $\delta^{18} \mathrm{O}$ values of randomly selected shells of Anisus (D.) vortex and Gyraulus (A.) crista from the six analysed sediment layers. Filled diamonds $-\delta^{13} \mathrm{C}$ values; empty diamonds $-\delta^{18} \mathrm{O}$ values

(2002) analysed only a limited number of sediment layers, of which two layers $(=25 \%$ of the studied layers) did not record the maximum range of isotope values, it is possible that an increased number of analysed sediment layers and a higher number of analysed shells could increase the observed range in $\delta^{18} \mathrm{O}$ values. However, it must also be noted that each lake has its own characteristics, including hydrology, morphology and climate. As a consequence, speciesspecific variability in isotope values of shells may differ from lake to lake. Thus, the use of isotope composition of mollusc shells in palaeoenvironmental studies must be preceded by verification of the variability in $\delta^{13} \mathrm{C}$ and $\delta^{18} \mathrm{O}$ values of the shells.

Our data provide evidence that the minimum number of shells required to provide a reliable mean isotope value and a wide range of values, was 15 . To verify this result, we calculated the optimum number of mollusc shells per sediment layer. The equation used to calculate the optimum sample size, i.e. the minimum number of individual shells that is needed to obtain an acceptable error for each stratigraphic level, was adopted from Escobar et al. (2010), Holmes (2008). Here, we tested the species Anisus (D.) vortex (Table 3), and for the six examined layers we got a calculated average of $\mathrm{N}=290$ for $\delta^{13} \mathrm{C}$ and $\mathrm{N}=1410$ for $\delta^{18} \mathrm{O}$ values. Surprisingly, but similar to the results achieved by Escobar et al. (2010), we generated an extremely wide range from the individual shells, between $\mathrm{N}=3$ and $\mathrm{N}=698$ for carbon and between $\mathrm{N}=190$ and $\mathrm{N}=2426$ for oxygen isotope composition (Table 3). Even though samples with high $\mathrm{N}$ values are desirable, such sample sizes are not feasible in most paleolimnological studies. On the other hand, if the $\mathrm{N}$ value is close to the lower limits of the above calculations, which is generally the case, it cannot be argued that the results are free of error. Because the calculations we provide here for average optimal $\mathrm{N}$ values are far from the postulated $\mathrm{N} \geq 15$ value, we performed an additional test, in which all samples with $\mathrm{N}$ values up to 20 were selected. As can be seen in Fig. 7, a sample size of $\mathrm{N} \geq 15$ seems to be the value at which stable and reasonable mean isotope values can be expected.
Although differences in mean isotope values of gastropod species were not a focus of the present study and will be discussed elsewhere, it is important to note that the observed differences in $\delta^{13} \mathrm{C}$ and $\delta^{18} \mathrm{O}$ values of the species (Figs. 3, 4) preclude analysis of subfossil mollusc shells from multiple species. Shells from different species should only be used in sequences with sparse mollusc shells. However, the accuracy of palaeoenvironmental inferences obtained from such multi-species samples can be compromised because each species has its own specific isotope values.

\section{Conclusions}

Analyses of the stable isotope composition of freshwater gastropod shells from the Paddenluch sediment sequence led to the following conclusions:

1. Differences between the minimum and maximum $\delta^{13} \mathrm{C}$ and $\delta^{18} \mathrm{O}$ values measured in mono-specific shells, sampled from a 1-cm-thick sediment sample, can be as large as several per mil. This variability stems from a combination of the isotope variability within the population, the life span of species, the thickness of the sampled sediment layer, the sediment accumulation rate and climatic and environmental changes during the time of sediment accumulation. Thus, individual shells are useless for characterizing the isotope value that is representative for the whole sediment layer.

2. The minimum number of shells that should be analysed per sediment layer was estimated using the method of random selection of shells. The number of shells that gave reliable mean isotope values was $N \geq 15$. Nevertheless, the minimum number of shells required for isotope analyses is strongly dependent on the isotope variability within the sediment layer, on the thickness of the sediment layer, on the sediment accumulation rate and on the environmental variability during the accumulation of sediment.

3. Multi-shell samples for $\delta^{13} \mathrm{C}$ and $\delta^{18} \mathrm{O}$ analyses should be mono-specific, as results of this study indicate that the mean isotope values differ between the species by $>2.5 \%$ for $\delta^{13} \mathrm{C}$ and $>3 \%$ for $\delta^{18} \mathrm{O}$. 
Acknowledgments This research was supported by the Polish Ministry of Science and Higher Education, Iuventus Plus Programme, Grant No IP2011 000471. We thank the employees of the Cemex OstZement GmbH and geologist A. Koszinski for help during fieldwork and for cutting the sediment block from the outcrop. We are grateful to Mrs. Małgorzata Schade for weighing the shells. Dr. Mariusz Gałka identified the plant fossil macroremains for ${ }^{14} \mathrm{C}$ analyses. Thanks are expressed to Drs. Danuta Michalska and Piotr Kołaczek for preparing the age-depth model and interpreting the ${ }^{14} \mathrm{C}$ data. We also thank Dr. Robert Spengler for correcting the English and Dr. Christian Leipe for drawing Fig. 1. Two anonymous reviewers are acknowledged for helpful comments on the manuscript.

Open Access This article is distributed under the terms of the Creative Commons Attribution 4.0 International License (http:// creativecommons.org/licenses/by/4.0/), which permits unrestricted use, distribution, and reproduction in any medium, provided you give appropriate credit to the original author(s) and the source, provide a link to the Creative Commons license, and indicate if changes were made.

\section{References}

Ahrens H, Lotsch D, Tessin R (1995) Die Entwicklung der Struktur Rüdersdorf und ihrer Umgebung im Känozoikum. Berl Geowiss Abh Reiche A 168:79-102

Anadón P, Utrilla R, Vázquez A (2002) Mineralogy and Sr-Mg geochemistry of charophyte carbonates: a new tool for paleolimnological research. Earth Planet Sci Lett 197:205-214

Anadón P, Moscariello A, Rodríguez-Lázaro J, Filippi ML (2006) Holocene environmental changes of Lake Geneva (Lac Léman) from stable isotopes $\left(\delta^{13} \mathrm{C}, \delta^{18} \mathrm{O}\right)$ and trace element records of ostracod and gastropod carbonates. J Paleolimnol 36:117

Anadón P, Utrilla R, Vázquez A, Martín-Rubio M, RodriguezLázaro J, Robles F (2008) Paleoenvironmental evolution of the Pliocene Villarroya Lake, northern Spain, from stable isotopes and trace-element geochemistry of ostracods and molluscs. J Paleolimnol 39:399-419

Apolinarska K (2013) Stable isotope compositions of recent Dreissena polymorpha (Pallas) shells: paleoenvironmental implications. J Paleolimnol 50:353-364

Apolinarska K, Hammarlund D (2009) Multi-component stable isotope records from Late Weichselian and early Holocene lake sediments at Imiołki, Poland: palaeoclimatic and methodological implications. J Quat Sci 24:948-959

Brauer A, Endres C, Negendank JFW (1999) Lateglacial calendar year chronology based on annually laminated sediments from Lake Meerfelder Maar, Germany. Quat Int 61:17-25

Bronk Ramsey C, Lee S (2013) Recent and planned developments of the program OxCal. Radiocarbon 55:720-730
Curtis JH, Hodell DA, Brenner M (1996) Climate variability on the yucatan peninsula (Mexico) during the past 3500 years, and implications for maya cultural evolution. Quat Res 46:37-47

Curtis JH, Brenner M, Hodell DA, Balser RA, Islebe GA, Hooghiemstra H (1998) A multi-proxy study of Holocene environmental change in the Maya Lowlands of Peten, Guatemala. J Paleolimnol 19:139-159

De Francesco CG, Hassan GS (2013) Stable isotope composition of freshwater mollusk shells from central-western Argentina. Rev Bras Paleontol 16:213-224

Escobar J, Curtis J, Brenner M, Hodell D, Holmes J (2010) Isotope measurements of single ostracod valves and gastropod shells for climate reconstruction: evaluation of within-sample variability and determination of optimum sample size. J Paleolimnol 43:921-938

Fiebig J, Schöne BR, Oschmann W (2005) High-precision oxygen and carbon isotope analysis of very small (10-30 $\mu \mathrm{g}$ ) amounts of carbonates using continuous flow isotope ratio mass spectrometry. Rapid Commun Mass Spectrom 19:2355-2358

Frömming E (1956) Biologie der mitteleuropäischen Süßwasserschnecken. Duncker \& Humblot, Berlin, p 313

Geist J, Auerswald K, Boom A (2005) Stable carbon isotopes in freshwater mussel shells: environmental record or marker for metabolic activity? Geochim Cosmochim Acta 69:3545-3554

Hailemichael M, Aronson JL, Savin S, Tevesz MJS, Carter JG (2002) $\delta^{18} \mathrm{O}$ in mollusk shells from Pliocene Lake Hadar and modern Ethiopian lakes: implications for history of the Ethiopian monsoon. Palaeogeogr Palaeoclimatol Palaeoecol 186:81-99

Hammarlund D, Edwards TWD, Björck S, Buchardt B, Wohlfarth B (1999) Climate and environment during the Younger Dryas (GS-1) as reflected by composite stable isotope records of lacustrine carbonates at Torreberga, southern Sweden. J Quat Sci 14:17-28

Hammarlund D, Barnekow L, Birks HJB, Buchardt B, Edwards TWD (2002) Holocene changes in atmospheric circulation recorded in the oxygen-isotope stratigraphy of lacustrine carbonates from northern Sweden. Holocene 12:339-351

Hodell DA, Curtis JH, Brenner M (1995) Possible role of climate in the collapse of Classic Maya civilization. Nature 375:391-394

Hodell DA, Brenner M, Curtis JH, Medina-González R, Ildefonso-Chan Can E, Albornaz-Pat A, Guilderson TP (2005) Climate change on the Yucatan Peninsula during the little ice age. Quat Res 63:109-121

Holmes JA (2008) Sample-size implications of the trace-element variability of ostracod shells. Geochim Cosmochim Acta 72:2934-2945

Hucke K (1922) Geologie von Brandenburg. Verlag von Ferdinand Enke, Stuttgart

Jones MD, Leng MJ, Eastwood WJ, Keen DH, Turney CSM (2002) Interpreting stable-isotope records from freshwater snail-shell carbonate: a Holocene case study from Lake Gölhisar, Turkey. Holocene 12:629-634

Jubitz KB (1993) Überblick über die Struktur Rüdersdorf und deren Stellung im geologischen Umfeld Ostbrandenburgs. In: Schröder JH (ed) Die Struktur Rüdersdorf. Führer zur 
Geologie von Berlin und Brandenburg. Selbstverlag Geowissenschaftler, Berlin und Brandenburg, pp 14-36

Kartographische Abtheilung der Königlich Preussischen Landesaufnahme (1877) Karte der Umgebung von Berlin und Potsdam. Sect. Rüdersdorf. Maßstab 1:25000

Kossler A (2010) Faunen und Floren der limnisch-telmatischen Schichtenfolge des Paddenluchs (Brandenburg, Rüdersdorf) vom ausgehenden Weichselhochglazial bis ins Holozän. Berl Paläobiol Abh 11:422

Leng MJ, Marshall JD (2004) Palaeoclimate interpretation of stable isotope data from lake sediment archives. Quatern Sci Rev 23:811-831

Lorrain A, Gillikin DP, Paulet Y-M, Chauvaud L, Le Mercier A, Navez J, André L (2005) Strong kinetic effects on $\mathrm{Sr} / \mathrm{Ca}$ ratios in the calcitic bivalve Pecten maximus. Geology 33:965-968

McConnaughey T, Gillikin D (2008) Carbon isotopes in mollusk shell carbonates. Geo Mar Lett 28:287-299

Reimer PJ, Bard E, Bayliss A, Beck JW, Blackwell PG, Bronk Ramsey C, Buck CE, Cheng H, Edwards RL, Friedrich M, Grootes PM, Guilderson TP, Haflidason H, Hajdas I, Hatté C, Heaton TJ, Hoffmann DL, Hogg AG, Hughen KA, Kaiser KF, Kromer B, Manning SW, Niu M, Reimer RW, Richards DA, Scott EM, Southon JR, Staff RA, Turney CSM, van der Plicht J (2013) IntCal13 and Marine13 Radiocarbon Age Calibration Curves 0-50,000 years cal BP. Radiocarbon 55:1869-1887

Shanahan TM, Pigati JS, Dettman DL, Quade J (2005) Isotopic variability in the aragonite shells of freshwater gastropods living in springs with nearly constant temperature and isotopic composition. Geochim Cosmochim Acta 69:3949-3966

Spötl C, Vennemann TW (2003) Continuous-flow isotope ratio mass spectrometric analysis of carbonate minerals. Commun Mass Sp 17:1004-1006

Strahl J (2005) Zur Pollenstratigraphie des Weichselspätglazials von Berlin-Brandenburg. Brandenburgische Geowissenschaftliche Beiträge 12:87-112

Taft L, Wiechert U, Riedel F, Weynell M, Zhang H (2012) Subseasonal oxygen and carbon isotope variations in shells of modern Radix sp. (Gastropoda) from the Tibetan Plateau: potential of a new archive for palaeoclimatic studies. Quat Sci Rev 34:44-56

Taft L, Wiechert U, Zhang H, Lei G, Mischke S, Plessen B, Weynell M, Winkler A, Riedel F (2013) Oxygen and carbon isotope patterns archived in shells of the aquatic gastropod Radix: hydrologic and climatic signals across the Tibetan Plateau in sub-monthly resolution. Quat Int 290-291:282-298

Xia J, Engstrom DR, Ito E (1997) Geochemistry of ostracode calcite: part 2. The effects of water chemistry and seasonal temperature variation on Candona rawsoni. Geochim Cosmochim Acta 61:383-391

$\mathrm{Yu} \mathrm{Z} \mathrm{(2000)} \mathrm{Ecosystem} \mathrm{response} \mathrm{to} \mathrm{Lateglacial} \mathrm{and} \mathrm{early}$ Holocene climate oscillations in the Great Lakes region of North America. Quat Sci Rev 19:1723-1747

Zanchetta G, Bonadonna FP, Leone G (1999) A 37-meter record of paleoclimatological events from stable isotope data on continental molluscs in Valle di Castiglione, Near Rome, Italy. Quat Res 52:293-299 